\title{
Implementation of FSO Network under the Impact of Atmospheric Turbulences
}

\author{
Sushank Chaudhary \\ Optical Technology Group, \\ InterNetworks Research Lab, \\ UUM ,Malaysia
}

\author{
Preety Bansal \\ Student \\ L.C.E.T Katani kala
}

\author{
Gurdeep Singh \\ Assistant Professor \\ L.C.E.T Katani kala
}

\begin{abstract}
This work is focused to carry out the investigations of Free Space Optical Transmission System under the impact of different atmospheric attenuation factors. In this work A 10 Gbps data is transmitted through free space optical link of 1 $\mathrm{km}$ and the performance is measured in terms of SNR, BER and eye diagrams. Further the role of modulation format is also investigated.
\end{abstract}

\section{General Terms}

Free Space Optics, Atmospheric Turbulences, Haze, Fog.

\section{Key Words}

Optical Wireless Systems, Modulation Formats, Free Space Optics.

\section{Introduction}

Now Days, Free Space Optical (FSO) Communication is one of major hot topics in the world of optical \& wireless communication. FSO communication is based on optical Communication with only difference that here the light signal which carries the information is not confined in to physical channel such as optical fiber. In FSO communication the optical signal is transmitted in to free space \& air or vacuum space act as a channel for signal transmission. This type of cable-less optical communication technology uses a highly directed narrow light beam to transmit data between two points [1]. It can avoid some challenges facing optical fiber communication such as high cost of digging roads, impractical physical communication between transmitter \& receiver. Also it can be presented to an alternative or an upgrade for long distance wireless communication system (up to few km's) [2]. Along with higher data transfer rate, a direct Line of sight FSO link offer several advantages compared to conventional wired \& radio frequency wireless communication. No need for licensed frequency band allocation, higher bit rate \& lower BER, immunity to EMI, very secure due to highly directionally $\&$ narrowness of beam are some of the several advantages of free space optics $[1,3]$. FSO Systems are mounted even within the building or top of the building / roofs. FSO System consists of mainly optical transceiver with a laser transmitter and receiver which allow it to transmit or receive the signal in full duplex mode. It generally looks like a video camera. Along with high power transceiver it also contains the lens which can transmits light through the atmosphere to other lens receiving information. If transmitter source does not produce a sufficiently parallel beam to travel the required distance, the collimation can be done with lens. The receiving lens further connects to high sensitivity receiver via optical fiber. Along with advantages of FSO communication, there are some factors that limit its performance. The main disadvantages of FSO communication system are strict alignment requirement \& adverse atmospheric weather condition. Achieving acceptable performance for a practical FSO link requires to overcome some major challenges at the transmitter such as determination of modulation techniques [4,5], suitable light source, transmitting wavelengths and also estimating transmitting power levels[6,7,8] .There are several challenges facing the channel performance such as effect of attenuation due to different weather condition that appears in study dealing with scattering $[9,10,11]$, atmospheric turbulences[12] and scintillations[13].This paper is organised as follow : System Description is mentioned in Section 2, Results are discussed in Section 3 followed by Section 4 which gives the conclusion of this work.

\section{SYSTEM DESCRIPTION}

There are three main important parts in the FSO System: Transmitter, propagation channel, and receiver. The FSO system is not much different from fibre optical communication where the difference relies in the propagation medium. In the OptiSystem software, the FSO link is modelled between an optical transmitter with $5 \mathrm{~cm}$ antenna and optical receiver with $20 \mathrm{~cm}$ optical antenna at each end. The transmitter converts the electric signal in to light. The light propagates through the atmosphere to receiver which converts light back in to corresponding electric signal. The FSO link is modeled between an optical transmitter and optical receiver. The attenuation of free space between two connecting FSO nodes is considered as $0.11 \mathrm{~dB} / \mathrm{Km}$ under clear weather conditions, $4 \mathrm{~dB} / \mathrm{Km} \& 22 \mathrm{~dB} / \mathrm{Km}$ under the impact of Haze and Fog respectively [14]. The transmitter and receiver gains are $0 \mathrm{~dB}$ by assuming both the antennas ideal. Also, scintillation and mis-pointing losses are not considered in this simulative work. At transmitting end, a 10-/40-Gbps data is generated by using a Pseudorandom Bit Generator. This data is fed to encoder and further modulated by using MZM modulator. A CW laser diode of line-width of $10 \mathrm{MHz}$ with power of $0 \mathrm{dBm}$ is used in our proposed hybrid system. At the reception end, the optical signal is received by Photo detector having a dark current of $10 \mathrm{nA}$ as shown in the Fig 1 . 


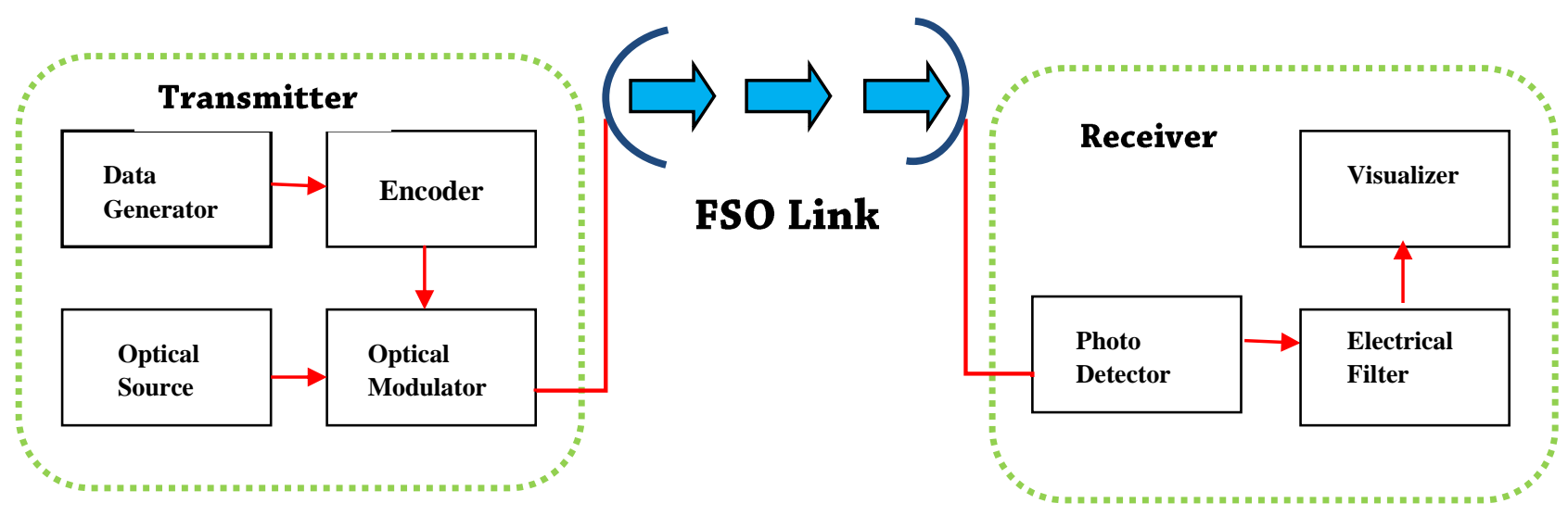

Fig 1 Architecture of Free Space Optical Transmission System

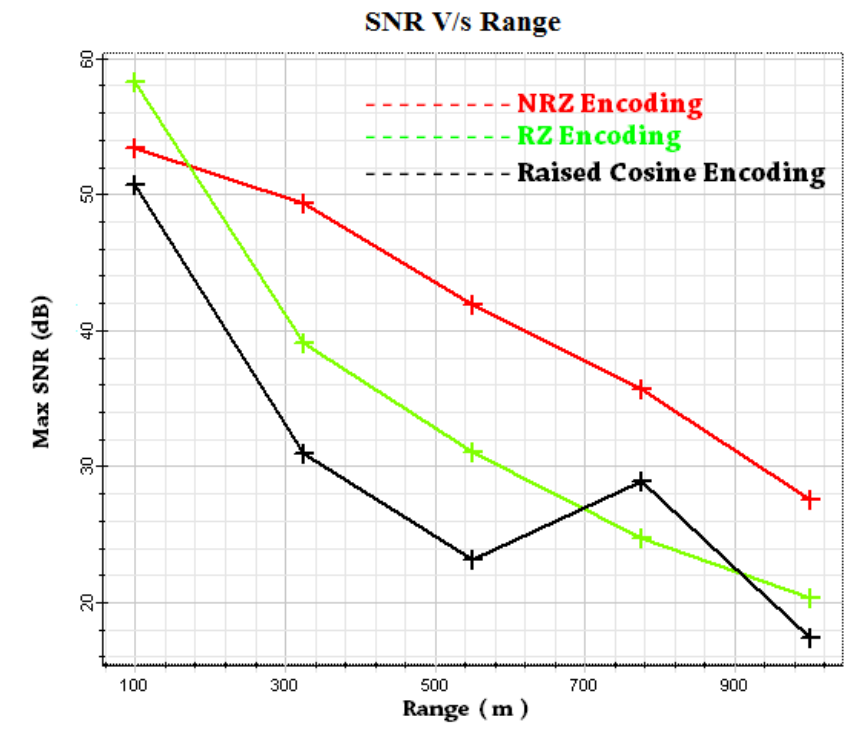

(a)

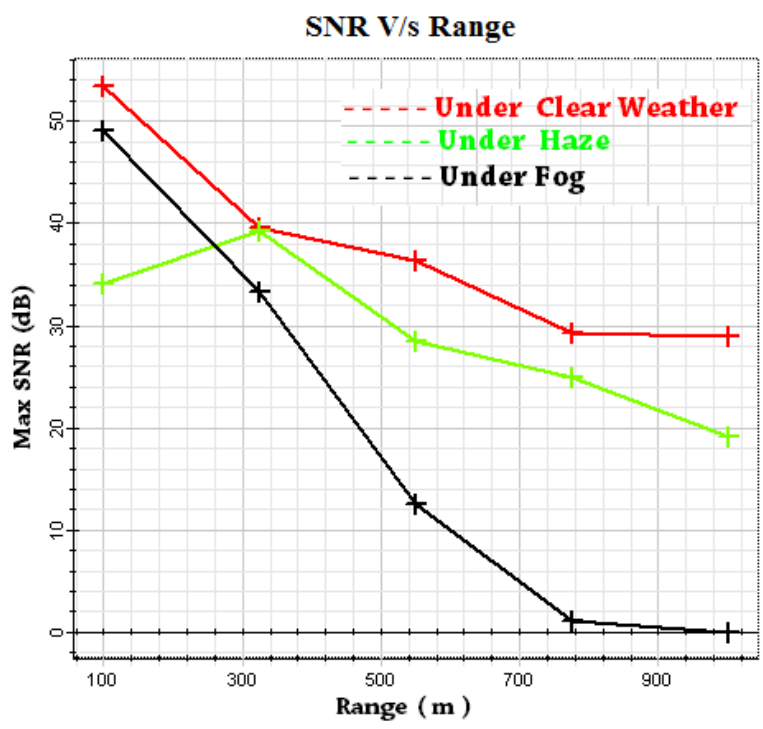

(b)

Fig 2 Evaluation of SNR Vs Range of FSO Link (a) Different Modulation Technique (b) Different Atmospheric Conditions 


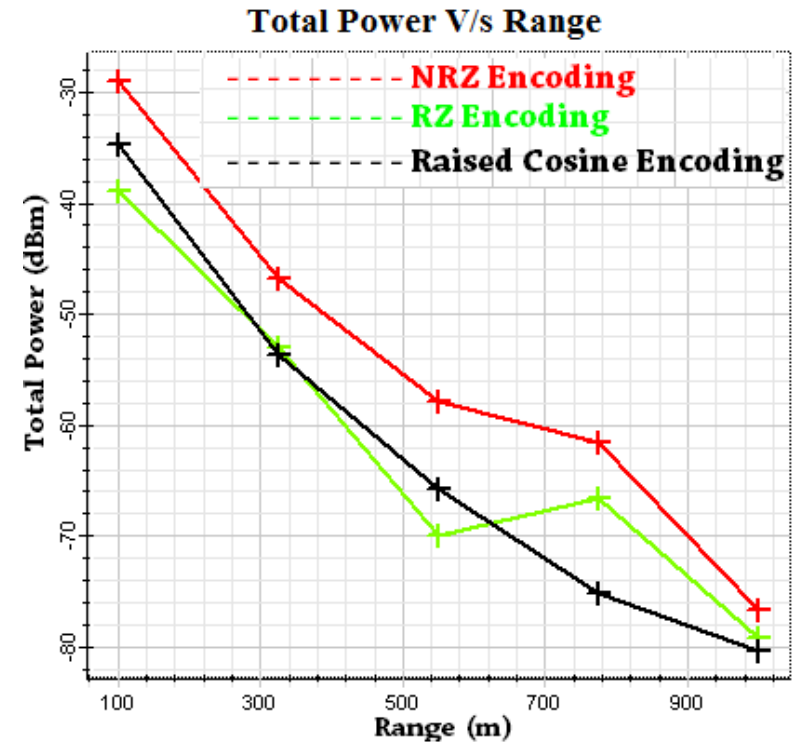

(a)

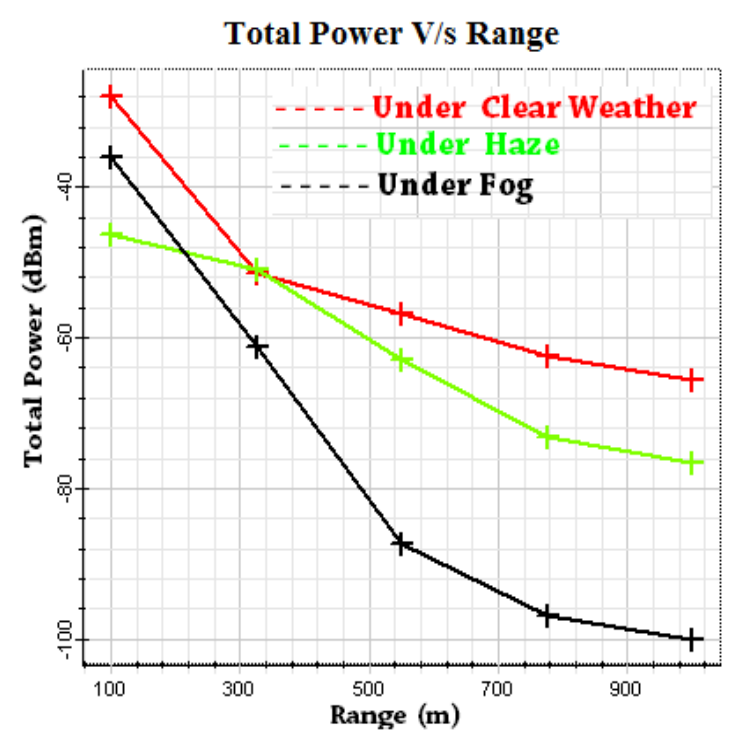

(b)

Fig 3 Evaluation of Total Power Vs Range of FSO Link (a) Different Modulation Technique (b) Different Atmospheric Conditions

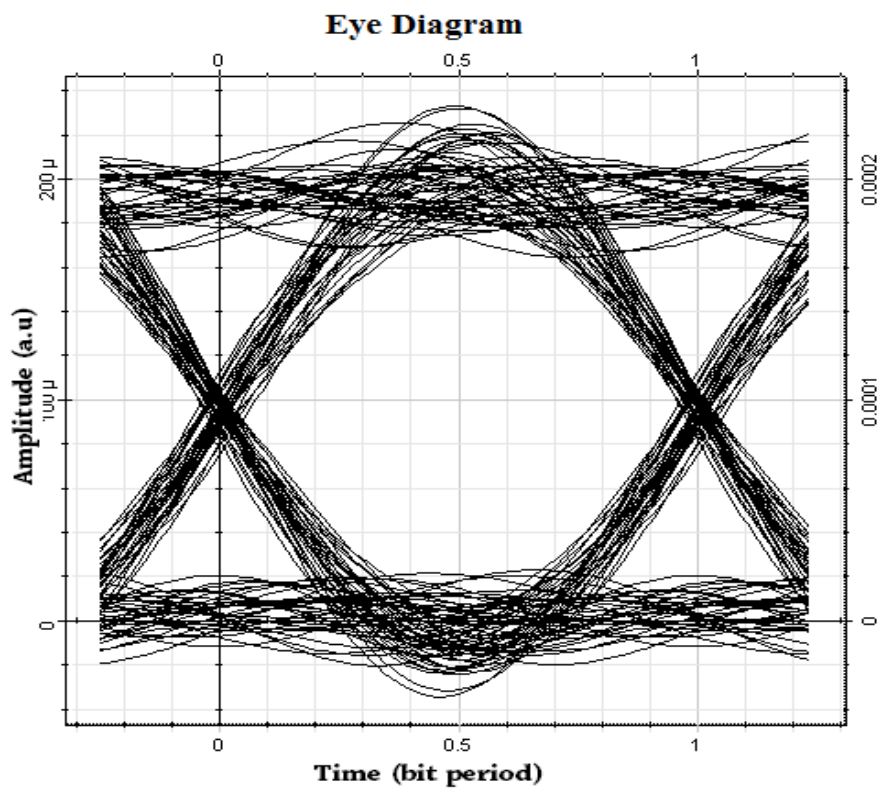

(a)

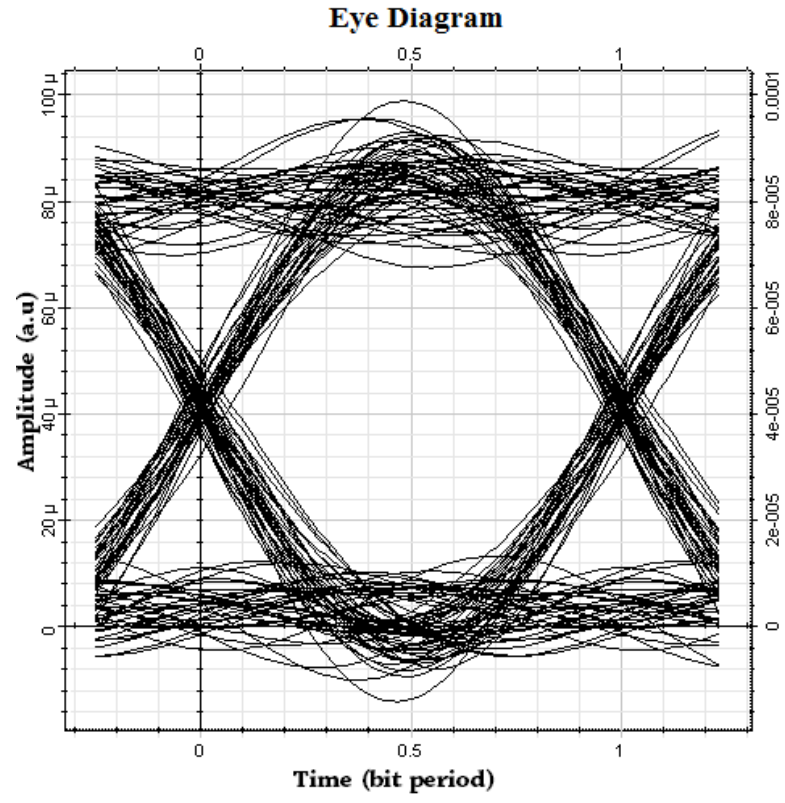

(b) 


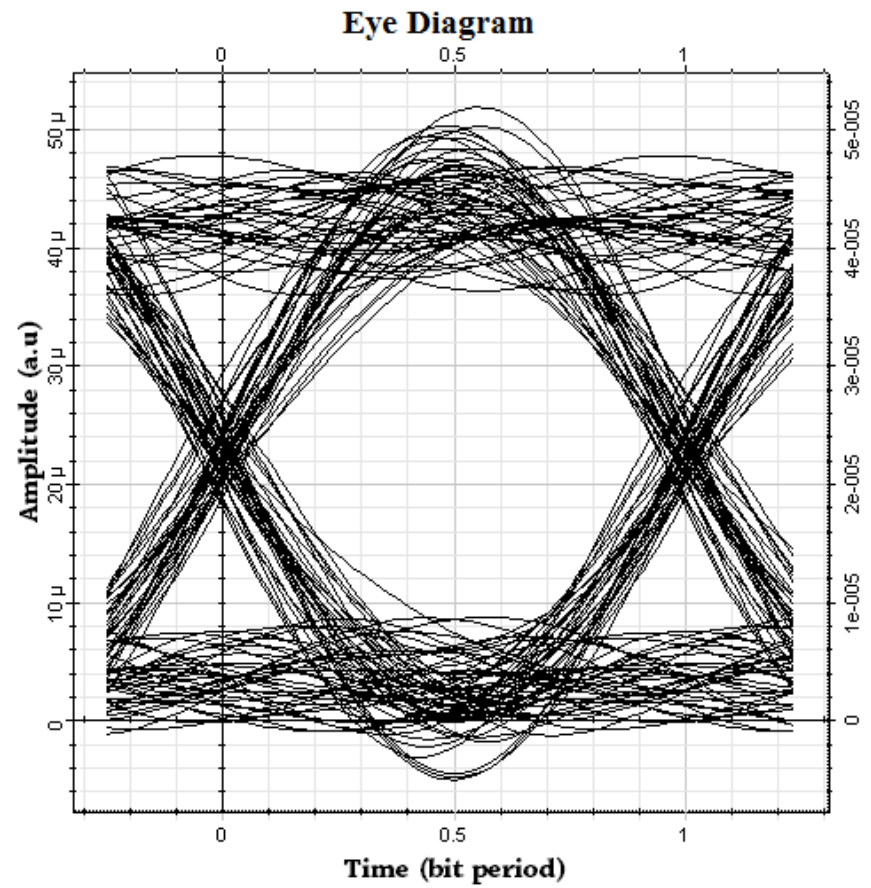

(c)

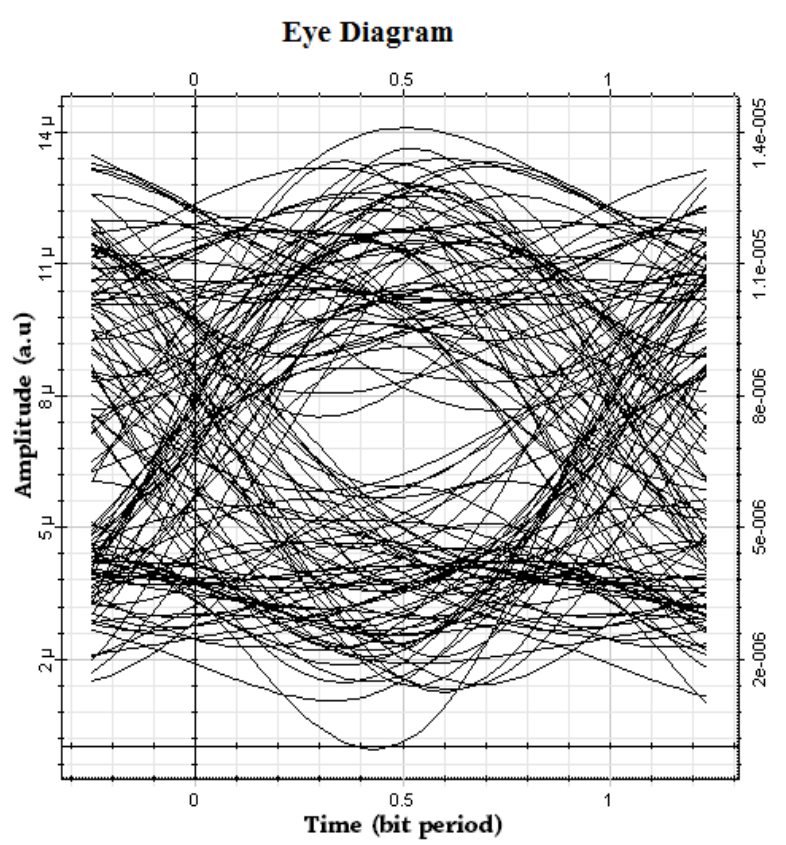

(d)

Fig 4 Evaluation of Eye Diagram at (a) Under Clear Weather Conditions after $1 \mathrm{Km}$ b) Under haze after $1 \mathrm{Km}$ (c) Under Fog after $550 \mathrm{~m}$ (d) Under Fog after $750 \mathrm{~m}$

\section{RESULTS AND DISCUSSION}

As data rates increase, FSO channels are better to be described as slow fading channels. So, according to information theory, any given transmission rate cannot be supported by such channels. Consequently, in many practical situations, where delay constraints prevent using of an extended codeword and averaging over deep fade channels realizations is not possible, an appropriate measure of capacity is the probability that the channel can support a given transmission rate. SNR is the required parameter to support a rate $\mathrm{R}$ and the probability of outage parameter can be expressed in terms of SNR. Further, it can be expressed in terms of the cumulative distribution function CDF of the SNR. Hence, in this work, we have discussed the results in terms of SNR by transmitting 10 Gbps signals via FSO link using different modulation technique and different atmospheric conditions. It is revealed from the Fig 2 (a) that an improvement of $8 \mathrm{~dB}$ in SNR after $1 \mathrm{Km}$ is computed in case of NRZ encoding scheme as compare to RZ \& Raised Cosine schemes. Fig 2 (b) reveals that FSO Link prolongs to 1 $\mathrm{Km}$ with the acceptable SNR of $30 \mathrm{~dB} \& 20 \mathrm{~dB}$ in case of under clear weather conditions and under haze whereas in case of under fog conditions it prolongs to only $500 \mathrm{~m}$ with the acceptable SNR of $20 \mathrm{~dB}$. Consequently, the total power received at photo detector is revealed from Fig 3. Similarly the eye diagram is evaluated for different atmospheric attenuations in Fig 4. The eye is clearer in case of clear weather conditions and under the impact of haze after $1 \mathrm{Km}$ FSO link as shown in Fig 4 (a) \& (b). Further when the attenuation is increased to achieve fog condition the eye is distorted after $500 \mathrm{~m} \& 750 \mathrm{~m}$ as shown in Fig 4 (c) and (d).

\section{CONCLUSIONS}

In this article, $10 \mathrm{Gbps}$ data of three modulation format is transmitted through free space optical link under three different atmospheric conditions and the performance is measured in terms of SNR, total power and Eye diagrams. It is concluded from the results that NRZ format is better as compared to RZ \& Raised Cosine modulation formats. Under Clear weather conditions the FSO Transmission link is prolongs to $1.3 \mathrm{Km}$. Under the impact of Haze the link prolongs to $950 \mathrm{~m}$ where as under Fog conditions the link prolongs to only $480 \mathrm{~m}$ with acceptable SNR and BER.

\section{REFERENCES}

[1] S Bloom, E. Korevaar, J Schuster and H.willbrand, "Understanding the performance of free space optics," J Opt. Networking., Vol. 2,no.6,pp. 178-200, June 2003.

[2] W.zhang,S. Hranilovic and C. Shi, "Soft switching Hybrid FSO/RF links using short length Rapter codes :Design and implementation, "IEEE J. Sel. Area comm., Vol. 27, no.9, pp. 1-11, December 2009.

[3] S.Arnon, "Optical wireless communication," In Encyclopaedia of optical engineering, pp. 1866-1886, New York, USA, 2000.

[4] W-D Zhong, S. Fu and C. Lin, " Performance comparison of different modulation formats over free space optical (FSO) Turbulence link with Space diversity Reception Technique,"IEEE photon.J.,vol. 1, no.6, pp. 277-285, December 2009.

[5] S.Rajbhandari et al, "On the study of the FSO link performance under controlled Turbulence and Fog atmospheric condition," $11^{\text {th }}$ International Conference on Telecommunications, ConTEL, G Raz, Austria, pp. 223226,june 2011. 
[6] X.Liu, “ Free space optics optimization Models for building Sway and Atmospheric Interference using variable wavelength," IEEE trans. Comm., Vol 57 no. 2, pp. 492-498, February 2009.

[7] D.K. Borah and D.G. Voelz, " Pointing error effects on free space optical communication links in the presence of atmospheric turbulence ," J.lightwave. Technol., Vol. 27, no. 18, pp. 3965-3973,September. 2009.

[8] H.G.Sandalidis, et al. "BER performance of FSO link over strong atmospheric turbulence channels with pointing errors,'IEEE Comm. Lett., vol.12.no.1,pp. 4446, January. 2008.

[9] I.I. kim, B.McArthur and E. Korevaar , "Comparison of laser beam propagation at $785 \mathrm{~nm}$ and $1550 \mathrm{~nm}$ in Fog and Haze for optical wireless communications," In proc. SPIE 4214, February.2001,pp. 26-37.

[10] M.S.Awan, Marzuki, E.Letigeb, F.Nadeem, M.S.khan and C.caposoni, "Weather effects impact on the optical pulse propagation in free space," In: proc. $69^{\text {th }}$ Vehicular Technology conference (VTC), Barcelona , April 2009.pp. 1-5.
[11] M.S.Awan, Marzuki, E.Letigeb, F.Nadeem, M.S.khan and C.caposoni, "Fog attenuation dependence on atmospheric visibility at two wavelengths for FSO link planning," Loughborough Antenna \& Propagation Conference, UK,pp.193-196,November. 2010.

[12] W.O.popoola and Z.Ghassemlooy, "BPSK subcarrier intensity modulated free space optical communications in atmospheric turbulence,"J. Lightwave Technol., vol. 27, no. 8, pp. 967-973,April 2009.

[13] W.O. popoola and Z.Ghassemlooy, C.G. Lee and A.C. Boucouvalas " Scintillation effect on intensity modulated laser communication systems- a laboratory demonstration ," J. Optical laser Technol., Vol. 42, no. 4,pp. 682-692,December 2009.

[14] Kim, B. McArthur, and E. Korevaar, Comparison of laser beam propagation at $785 \mathrm{~nm}$ and $1550 \mathrm{~nm}$ in fog and haze for optical wireless communications, Proc. SPIE, Vol. 4214,p. 26-37, Optical Wireless Communications III, edited by Eric J. Korevaar (2000) 